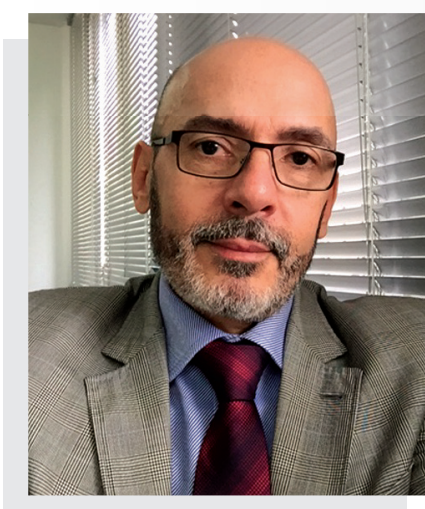

https://doi.org/10.24207/jac.v32i1.995_IN

EDITORIAL

\title{
A Constant Process of Renovation
}

\section{Um Processo Constante de Renovação}

\section{J. Tarcísio Medeiros de Vasconcelos}

The year of 2019 brought us unforeseeable surprises, new challenges, new goals, new motivations. This is how we see the process going.

As of April, we made changes in the editorial staff. Ana Marlene F. Morais assumed the executive editor of this journal, bringing her expertise and extensive experience. As a member of the board of the Brazilian Association of Scientific Editors (ABEC Brasil), she enjoys respect and broad knowledge in the area of scientific publishing. She began her work with a series of suggestions that meet the expectations of technical and scientific aggrandizement of the journal. The first one, and that has already materialized in this first edition of this year, is the adequacy of formatting of the journal to the requirements of indexation to important international databases. The second one also made concrete in this edition, is the already ambitious transformation of the journal into a vehicle published in English and entitled Journal of Cardiac Arrhythmias (JCA). In fact, more than that, from now on, the JCA will become a bilingual journal, published in Portuguese and English. This, in addition to bringing necessary adaptations to future other indexing, brings respectability to the journal and provides international visibility by allowing easy access to your content in any country. This is our goal: to make JCA a vehicle of scientific information that is respectable and attractive for good publications, access to all the community of researchers lacking a journal in our specialized area in cardiac arrhythmias.

Happy reading! 